The Handbook of Privacy Studies 



\title{
The Handbook of Privacy Studies
}

\author{
An Interdisciplinary Introduction
}

Edited by

Bart van der Sloot \& Aviva de Groot 
Cover design: Moker Ontwerp

Lay-out: Crius Group, Hulshout

$\begin{array}{ll}\text { ISBN } & 9789462988095 \\ \text { e-ISBN } & 9789048540136 \\ \text { DOI } & 10.5117 / 9789462988095 \\ \text { NUR } & 740\end{array}$

(C) The authors / Amsterdam University Press B.V., Amsterdam 2018

All rights reserved. Without limiting the rights under copyright reserved above, no part of this book may be reproduced, stored in or introduced into a retrieval system, or transmitted, in any form or by any means (electronic, mechanical, photocopying, recording or otherwise) without the written permission of both the copyright owner and the author of the book.

Every effort has been made to obtain permission to use all copyrighted illustrations reproduced in this book. Nonetheless, whosoever believes to have rights to this material is advised to contact the publisher. 


\section{Contents}

Introduction $\quad 7$

Bartvan der Sloot \& Aviva de Groot

1. Privacy from a Historical Perspective

Sjoerd Keulen \& Ronald Kroeze

Legislating Privacy: Technology, Social Values, and Public Policy

Priscilla Regan

2. Privacy from a Legal Perspective

Bartvan der Sloot

Three Dimensions of Privacy

Beate Roessler

3. Privacy from an Ethical Perspective

Marijn Sax

Nudging: A Very Short Guide

Cass R. Sunstein

4. Privacy from an Economic Perspective

Edo Roos Lindgreen

Security, Privacy, and the Internet of Things (IoT)

Mikko Hypponen

5. Privacy from an Informatics Perspective

Matthijs Koot \& Cees de Laat

Political Science and Privacy

Charles Raab

6. Privacy from an Intelligence Perspective

Willemijn Aerdts \& Giliam de Valk 
A Privacy Doctrine for the Cyber Age

Amitai Etzioni

7. Privacy from an Archival Perspective

Tjeerd Schiphof

Medical Privacy: Where Deontology and Consequentialism Meet Robin Pierce

8. Privacy from a Medical Perspective

Wouter Koelewijn

Privacy Law - on the Books and on the Ground

Kenneth A. Bamberger \& Deirdre K. Mulligan

Jo Pierson \& Ine Van Zeeland

Diversity and Accountability in Data-Rich Markets

383

Viktor Mayer-Schönberger

10. Privacy from a Communication Science Perspective

387

Sandra Petronio

Still Uneasy: a Life with Privacy

409

Anita LaFrance Allen

11. Privacy from an Anthropological Perspective

Sjaak van der Geest

About the Authors 


\section{Introduction}

\section{The background of this book}

It was the beginning of 2010 when I (Bart) first joined the University of Amsterdam as a privacy researcher. What struck me immediately were two things: how interdisciplinary the topic of privacy was and how limited the interaction was between the different fields, disciplines, and researchers from the various faculties at the university. Out of personal interest and a desire to map the field of privacy, I decided to invite for coffee and formally interview over 50 colleagues about their privacy research. It brought me to the fields of medicine, anthropology, economy, political science, informatics, philosophy, law, sociology, communication science, psychology, and a couple more.

I think I failed miserably at grasping and properly describing everyone's research in the small report I made on the basis of the interviews. Although privacy was certainly the central theme, the role it played in the various disciplines, the methodology they used, and the types of questions scholars were trying to answer varied widely, not to mention the jargon. Some philosophers tried to define the universal value of privacy, while anthropologists and sociologists stressed its contextual and cultural nature; while political scientists viewed data as means of power and control, lawyers tended to see privacy as a right to be safeguarded from intrusions; in communication science and economy, personal information was seen primarily as an asset, while informaticians focused mainly on building secure and confidential information systems without any data leakage.

What became clear from the interviews was that each researcher felt that in order to properly discuss and answer research questions within his own field of research, he needed to have insight into aspects from other disciplines. People working at the informatics department, for example, built information systems in health care environments, and sought a better grasp of informational secrecy and doctor-patient confidentiality in order to properly design infrastructure. People at the medical department of the university called for more knowledge about the legal protection of patient data and the exception in law for using their data for scientific (medical) research. Faced with the different approaches in different countries and regions in the world, lawyers wanted to have more insights from the fields of sociology and anthropology. And people working within the latter disciplines often were more than interested in the ethical debates about values and principles underlying the right to privacy. 
At the same time, people stressed that their knowledge of other fields and disciplines was limited. So I started organizing bimonthly research meetings, each time with two or three speakers from different backgrounds and disciplines, to discuss their research and get feedback from the audience and learn from each other. Gradually, we became more formal and structurally connected and Nico van Eijk (Faculty of Law), Guido van 't Noordende (Faculty of Science), until he left the university, Beate Roessler (Faculty of Humanities), Edo Roos Lindgreen (Faculty of Economics and Business), and I formed the spearhead leading the initiative now officially coined the Amsterdam Platform for Privacy Research (APPR).

We decided to organize public seminars and meetings, aimed at a broader audience. Although right now - at least in Europe - privacy is high on the political agenda, 2010 and 2011 were the years that 'I've got nothing to hide' and 'privacy is dead' dominated as slogans. We felt that it was necessary to explain in what ways privacy plays a role in many aspects in work and life. Doing so, APPR grew to be the organisation it is today - a network of more than 70 scholars at the University of Amsterdam that do research on aspects related to privacy.

We decided to expand and organized the Amsterdam Privacy Conference 2012 and the Amsterdam Privacy Conference 2015, which aimed to be a truly interdisciplinary conference, going beyond the many law and tech (sometimes with the inclusion of ethics) seminars and workshops already taking place. The Amsterdam Privacy Conference 2018 is being organized as we write this introduction. Finally, we felt that not only our own research community and the international research community would benefit from the interdisciplinary approach to privacy research, but students as well. I started the interdisciplinary privacy course, which after two years evolved into the minor Privacy Studies, which was attended by Aviva de Groot (the second editor of this book), who then took over the coordination of the minor programme.

Although my personal interest in privacy was already well developed during my earlier career in the film industry, I (Aviva) first engaged with privacy professionally when I entered legal practice. At that time, the European Commission had just issued its first communication on the reform of data protection law, and the focus on informational privacy had become predominant. The Amsterdam Minor Privacy Studies provided a timely programme promoting a broader and deeper understanding of a concept that was increasingly being discussed as nearing extinction.

The rich notions of privacy that interdisciplinary study offers easily resonate with lay conceptions that students develop earlier on in life. In my case, 
the early 70's represented the late age of a 'social conventions battlefield', in a country where some families had already learned to shed their identities after the Second World War. My contemporaries and I explored the ruinous landscapes with both curiosity and vigilance. Just like confinement, we observed that exposure can both be life-ruining and life-threatening. Later, academic literature on privacy and the broad relevance of the principles that it addressed deepened my retrospective understanding. The feminist critiques and debates were of special relevance in their insights into the politics of privacy.

The first edition of the minor programme already took place in the 'I have nothing to hide' era. Students' traditional starting assignment was - and still is - to define and argue their individual notion of privacy. When I took over the coordination of the minor from Bart, I saw students surprised to find the solemn voice of law echoing some of their heartfelt notions. They were intrigued and curious about the law's lacunas, and its paternalistic potential. They were relieved to find there is no need to resort to law to sustain any argument, and that supposed dichotomies (like that of privacy versus security) could also be seen as interdependent relations. However, characterizations of privacy as (either/or) rights, freedoms, values, defined by breaches or by context, by ethical or cultural norms, narrowed down to intimate aspects or tradable data, often made for confusing discussions. In the afterhours of many a lecture, students confessed to being overwhelmed. The different vocabularies, academic cultures and methods of the disciplines, in addition to those of the students themselves, posed challenges to the conception of a cross-disciplinary, comprehensive understanding that they wanted to develop.

These discussions and other interdisciplinary teaching experiences partly informed the design of this book. And although it is called 'The Handbook of Privacy Studies,' we aim to do justice to the diversity not only between, but also within the disciplines, which is reflected in the chapter's titles that present $a$, rather than the perspective from their discipline. We hope this book sustains the analysis of common understandings and differences, so that these can be taught in a meaningful way.

\section{Why this book?}

The reason to initiate and edit this book was to promote the interdisciplinary line of privacy research we had built over the past few years at the University of Amsterdam. It is also the combined result of our continued search for 
an interdisciplinary understanding of privacy, and a way to share these insights with students of different disciplines. Since the idea for this book was developed during the discussions at APPR meetings and the minor programme, many of the authors are based in Amsterdam. Others have their roots there. Bart and Aviva now work at the Tilburg University, Willemijn Aerdts and Gilliam Valk decided to move from the University of Amsterdam to Leiden University, and Matthijs Koot started working for a security firm. Still other authors were either teachers for the minor programme, such as Jo Pierson, students of the minor programme, such as Ine van Zeeland, or keynote speakers at the Amsterdam Privacy Conferences, such as Sandra Petronio, Deirdre Mulligan, Viktor Mayer-Schöberger, Anita Allen, and Amitai Etzioni. Some new faces also appear, such as Robin Pierce, Miko Hypponen, and Cas Sunstein.

This book is intended for three types of audiences:

- It is written for privacy researchers who are interested in other fields of research. Suppose you are a lawyer and are faced in your research with aspects of ethics and informatics - this book will provide you with a basic understanding of those disciplines and suggest further readings on specific topics that may be of interest to you. The chapters are written so that a researcher from every scientific background should be able to understand the disciplinary approach to privacy from every other academic discipline.

- It is written for students who are interested in privacy from a multidisciplinary background. It can be used as a basic textbook in interdisciplinary educational programmes such as the minor Privacy Studies. It can also be used for disciplinary courses of which privacy is one of the aspects. A chapter may be used to explain to a student what, among other themes and topics, the role of privacy is from the perspective of the discipline covered in that chapter.

- It is also written for a general audience interested in privacy. Privacy is in the news almost every day - Facebook and Cambridge Analytica, hacks and political profiling, medical research and big data technology, the General Data Protection Regulation, and mass surveillance by intelligence agencies, etc. This book will provide you with more background information about these developments and how to understand and properly evaluate them.

Privacy itself is a multidisciplinary phenomenon. A common 'playground' and language needs to be instated for researchers to present the role of privacy within their discipline, and the interdisciplinary value of their 
knowledge to a common understanding of privacy. When Aviva and Ine presented the minor and its challenges at the National Interdisciplinary Education Conference, the need for something that could be conceptualized as 'a handbook' was shared widely. Calls included 'a red thread', 'oversight', 'tables with aspects', 'a reader for teachers', 'creative examinations', and 'strictly structured lecture schemes'.

This book caters to some of these needs. It is the first book that makes an earnest attempt at bringing together some of the most important disciplinary approaches in the field of privacy in a comprehensive way. Nevertheless, it is only a first scan and a selection of relevant disciplines. We already envisage a second edition that includes fields that were also part of the minor and that we are eager to incorporate, such as psychology, sociology, architecture, internet studies, and political science. This first edition contains chapters on history, law, ethics, economy, informatics, intelligence studies, archival studies, medicine, media studies, communication studies, and anthropology. We asked each author to provide the reader with an introduction to her field of research, the role privacy plays within that discipline, to introduce the reader to the classic texts that have helped shape that discipline, and to map the debates and schools that have been dominant over the past few decades. Finally, we have asked them to list a number of questions on their current research agenda (or that of their peers) - what are the difficult challenges, what burning dilemmas are provoked by new technological developments, and what unresolved issues remain to be addressed by scholars? Each chapter concludes with a few suggestions for further reading.

Between those chapters, introducing the disciplinary approaches to privacy, we have added small snippets and reflections by famous authors and defining intellectuals in the field of privacy. We are honoured to have a star line-up of Priscilla Regan, Beate Roessler, Cass Sunstein, Miko Hyponen, Charles Raab, Amitai Etizoni, Robin Pierce, Kenneth Bamberger, Deirdre Mulligan, Viktor Mayer-Schönberger, and Anita Allen. Like soloists to the orchestra, these voices lead but also resonate with the score produced through the combined effort of the book's authors.

After all these years, our interdisciplinary privacy research meetings frequently result in discussions about what a person precisely means to say, or why certain research questions are valid at all. Although some researchers have seized the opportunity to work together and expand to multi- or interdisciplinary research, most are still clearly centred in their own field of research. In part, this stems from the perception that what is considered to be essential research, ground-breaking research, works that attract funding and positions, are still mostly disciplinary. We were 
therefore quite surprised to be faced with quite the opposite problem upon receiving the first draft chapters. We had specifically asked authors to keep to their own discipline. To introduce it, to explain what role privacy plays within it, what debates about privacy exist in their discipline and in their specific research. Almost every author took an interdisciplinary or at least multidisciplinary approach. Had they finally come to, had we asked them to revive old habits? We were especially surprised that many authors chose to discuss legal aspects - either laws, codes of conducts, case law, or specifically legal authors such as Warren \& Brandeis. Perhaps it reflects the character of present-day privacy research.

\section{Content of this book}

The first chapter is on history, written by Ronald Kroeze and Sjoerd Keulen. They argue that the history of privacy shows that privacy is an ever-changing and context-dependent phenomenon. As such, opportunities for and threats to privacy are highly related to broader societal developments. Several of these broader developments are been distinguished and discussed and we briefly sum them up here. First, changing morals, cultural and religious ideas about the individual, family, household, and 'natural' relationships have had an effect on individual privacy. Second, privacy has been influenced throughout history by political changes, especially the rise of the idea of private individual rights and the acceptance of an individual sphere that the state, society, and legal system should respect and protect. Furthermore, the development of liberal-democracies - with individual freedom and the non-interference principle as its core values - and the internationalization of human rights in the past decades, have had a big impact on the politics and history of privacy. Finally, as the first but certainly not the only chapter to address the fact that technological changes, especially in the field of infrastructure, media, and communication, have had and will have great impact on privacy matters. For those that started the book (and the chapter) expecting a definite overview of the history of privacy, the chapter may serve as a 'training phase': rather than provide accounts and definitions, the chapters of this book afford insight into the disciplinary lives of privacy, and how each discipline takes care of the subject.

A snippet by professor Priscilla Regan introduces her seminal text Legislating Privacy: Technology, Social Values, and Public Policy (1995), in which she argued that privacy is not only of value to the individual but to society in general as well. She also suggested three bases for the social importance of 
privacy: its common value, its public value, and its collective value. Her thinking about privacy as a social value was informed both by the philosophical and legal writing at the time, as well as by legislative politics and processes in the United States that sought to protect a 'right to privacy'. She concluded that the individualistic conception of privacy, popular in the 196os and 1970s, did not provide a fruitful basis for the formulation of privacy protective policy. When privacy is regarded as being of social importance, she argued, different policy discourse and interest alignments are likely to follow. Regan's text provides a natural bridge from broader social/societal understanding of privacy to commencing to learn about the subject in more legal detail.

The second chapter is written by Bart van der Sloot. He explains that rather recently, privacy has been incorporated into human rights instruments such as the Universal Declaration on Human Rights and the European Convention on Human Rights. The European Court of Human Rights has granted the right to privacy, provided under Article 8 ECHR, a very broad scope, covering almost every aspect of a person's life. The EU Charter of Fundamental Rights contains a right to data protection, in addition to a right to privacy. Data protection is regulated in the EU by the General Data Protection Regulation. The GDPR provides detailed rules on how and when data controllers may legitimately process personal data of citizens. Famous rules include the purpose limitation, data minimalization and storage limitation principle, the right to be forgotten, the right to resist profiling, and the obligation to perform data protection impact assessments. We have put this chapter in the front row for various reasons. One is the earlier mentioned fact that the legal discourse is particularly big, broad and growing. Another is that several authors expressed the wish to refer to this chapter directly, to avoid conceptualizing legislative aspects in theirs. That is why this chapter is substantially bigger than the other ones; it provides a point of reference for the other disciplines.

The next snippet is written by Beate Roessler, who discusses her widely cited book The Value of Privacy. In this book, she discusses three dimensions of privacy: locational privacy, informational privacy, and decisional privacy. She argues that conceptions of privacy based upon a concept of autonomy or individual freedom provide the most interesting and forward-looking possibilities for a conceptualization of the term. The three dimensions - not realms, not spaces - of privacy serve to protect, facilitate, and effectuate individual liberties in a variety of respects. Freedom-oriented theories of privacy are to be found within the whole range of theories of privacy, from those that deal with the privacy of (intimate) actions to those concerned with informational privacy or the privacy of the household. 
The third chapter, dealing with the ethical perspective, logically follows. It is written by Marijn Sax. As both society and technology are constantly developing and changing, he argues, we are also confronted with a constant reconfiguration of norms that regulate what we may know of each other, what we may see of each other, what places we may enter, what information we may share, and what private decisions we may (try to) influence. Many of the theories discussed are an attempt to (1) make sense of these shifting norms, and (2) suggest how we should, ideally, understand and enforce privacy norms. Marijn Sax explains, inter alia, the difference in ethics between access-based and control-based approaches to privacy.

At this stage in the book, where privacy-as-autonomy has been properly introduced, a following snippet is presented by Cass Sunstein, who offers a general introduction to the idea of 'nudging', the theory of manipulating people's choices to serve their own well being. A list of the most important 'nudges' illustrates the practice. Nudging was made famous by the book Nudge he wrote together with Richard Thaler. The snippet also provides a short discussion of the question whether to create some kind of separate 'behavioural insights unit', capable of conducting its own research, or instead to rely on existing institutions. The snippet is followed by a chapter on a discipline that addresses the costs and benefits to privacy of the actors on either side of the nudging (and other) business, and takes an economical perspective.

This fourth chapter is written by Edo Roos Lindgreen. The chapter explores an economical approach to privacy. Roos Lindgreen identifies and clarifies various factors of influence on the economics of privacy in the digital age. As it turns out, it is relatively easy to identify positive economic factors (benefits) and negative economic factors (costs) of privacy for individuals, organizations, and society at large. For individuals, controlling the disclosure of personal data has significant direct benefits, but also leads to opportunity costs: the indirect costs of not being able to enjoy other benefits. For private and public organizations, collecting and using personal data leads to significant economic benefits; prohibiting them from doing so will erode their competitive advantage and incur opportunity costs. For society at large, however, the situation is quite unclear.

The next snippet by IT-expert Miko Hypponen takes a leap into the architecture beneath the applications and techniques at play in the former chapter. Hypponen argues that the Internet wasn't built for security or privacy. We built it first and have had to play catch-up to secure it afterwards and are still working on that, all the time. Unfortunately, the Internet of Things was not 'built' for security either. But it's not too late. We need to 
take the Internet of Things' security seriously, and do it now, before the problems caused by neglecting it become too difficult to handle. By now, some of these problems are (un)fortunately foreseeable.

The former snippet introduced an important subject, and maybe the hardest one to present in a way that serves all envisaged categories of readers: the informatics perspective. Matthijs Kootand Cees de Laat, working at the University of Amsterdam, have taken it upon themselves to author the chapter. They explain how ICT poses privacy challenges, and how privacy poses ICT challenges. Selected topics relating to both perspectives are discussed. From a technical perspective, cryptography, PETs, and access controls are building blocks for privacy and data protection. They discuss the various challenges of building secure and safe systems and networks. The chapter is salient in a time where governments are intensively exploring the use of these techniques, directly and indirectly funding developments, and taking sides in the ensuing public discourse on privacy that in the process frequently narrows down to data protection. Which takes us naturally to the subjects of politics and intelligence studies.

Charles Raab activates the appropriate mental muscles in his snippet, where he argues that contributions to the study of information privacy issues can be grounded in empirical research and analytical approaches derived from the discipline of political science. Moreover, research and commentary on other dimensions of privacy besides the informational one serve to broaden the field and constructively blur the boundary that has developed between information privacy and other domains of privacy: e.g. the body, public and private space, thoughts and movement. Governance and regulatory regimes (including the law) and policy activity for these other objects of study could also be investigated as part of the analysis.

The fifth chapter logically follows with the intelligence perspective on privacy, written by Willemijn Aerdts and Gilliam Valk. They suggest that next to the rather 'technical' debate about the degree to which intelligence- and security services are allowed to invade personal space and infringe upon the right of privacy, there is a debate on how services are to actively protect civilians and their personal rights. Data mining is an important instrument of intelligence- and security services. Being able to collect, process, and analyse big data and the search for suspicious correlations seem to be indispensable to avert threats. Henceforth, an adequate oversight is of utmost importance. As shown in this chapter, this relates to the position of services and their special power in the democratic legal order (proportionality), the confidence and trust society has in the services, and the prevention of the abuse of special powers. 
Amitai Etzioni has given these matters ample thought and has provided analyses throughout his career. In this snippet, he shows that in order to maintain privacy in the cyber age, boundaries on information that may be used by the government should be considered along three major dimensions: (1) the level of sensitivity of the information; (2) the volume of information collected; and (3) the extent of cybernation. These considerations guide one to find the lowest level of intrusiveness while holding the level of common good constant. A society ought to tolerate more intrusiveness if there are valid reasons to hold that the threat to the public has significantly increased (e.g. there is a pandemic), and reassert a lower level of intrusiveness when such a threat has subsided.

From the field of security, the book turns to two other disciplines in which the need to limit privacy is a central element: archival sciences and medicine.

The sixth chapter is written by Tjeerd Schiphof, who discusses the relationship between archival studies and privacy. He explains how Privacy issues are salient in the archival field. For example, individuals might experience harm because of the fact that certain materials will be stored for the long term, and so can be accessed during their lifetime. The archival institutions, private and governmental, and individual archivists have considerable responsibilities in this respect, especially at certain stages in the archival process. Schiphof explains how archivists need to navigate a sometimes complex field of law, professional ethics and national and international standards, and how these are challenged by the affordances of new technologies.

This is followed by the introduction to another field where professional ethics play an important role, and where much is asked from individual practitioners and of the field as a whole. In her snippet, Robin Pierce discusses privacy from a medical perspective. She stresses the importance of intersecting normative strands of medical privacy, derived from different sources, to form a set of norms designed to protect a bundle of interests that is essential to the maintenance of an effective healthcare system that encourages and protects appropriate care-seeking and treatment. Whether and how technological changes in the collection, storage, and processing of data affect the construct of medical privacy is a pressing question. Just as a bell cannot be unrung, erosion of the sphere of medical privacy is unlikely to be restored. The eager embrace of technological innovation such as big data, machine learning, AI, eHealth, data sharing, essentially forming a virtual explosion of connectedness is likely to present challenges to the construct of medical privacy. She argues for the teleological basis for medical privacy and suggests that at least one aspect of evaluating and potentially 
remedying instances of erosion is assessing the impact on the ability of the current construct of medical privacy to achieve its objectives.

In the seventh chapter, Wouter Koelewijn channels this focus of medical privacy to explore in depth the data protection norms and regulations at play in healthcare relationships. He underlines the high importance of privacy and data protection in this sector, and addresses the challenges of bridging legal complications and contradictions that entail the right to privacy ands doctor-patient confidentiality, especially in light of the development of electronic information systems for the storage of medical data - and in those of e-Health, big data, and artificial intelligence in healthcare. Changes in the perceptions of patients and physicians vis-à-vis each other and adaptations of the data-protection concepts seem inevitable.

In an interesting follow-up after discussing the interplay of law and professional ethics, Kenneth Bamberger and Deirdre Mulligan suggest in their snippet that for too long, scholarship and advocacy around privacy regulation has focused almost entirely on law 'on the books' - legal texts enacted by legislatures or promulgated by agencies. By contrast, the debate has surprisingly ignored privacy 'on the ground' - the ways in which those who collect and control data in different countries have (or have not) operationalized privacy protection in the light of divergent formal laws, decisions made by local administrative agencies, and other jurisdiction-specific social, cultural, and legal forces. They introduce their influential book, Privacy on the ground.

Having made the shift from the books and to the ground, we continue to focus on human interaction, and how this is increasingly mediated, influencing many privacy aspects. The eighth chapter, written by Jo Pierson and Ine van Zeeland, discusses the field of media studies. They argue that given the transition from social media to online platforms, the media-studies perspective generates a uniquely interdisciplinary insight into how these digital media and society mutually articulate each other. This is particularly relevant as these media and technologies are penetrating all fibres of society, from social communication to domains like health, education, mobility, urban life, and smart cities. Consequently, the need to investigate and address fundamental public values like privacy and data protection from a media and communications perspective will only increase. Media are thereby interpreted in a broad sense, namely as technological tools that mediate the interaction between people. After this chapter, it is high time to re-visit the players that make these mediated communications possible, and how they do it. 
Viktor Mayer-Schönberger, famous for many books such as Big Data and Delete, argues in his snippet that today's data-rich markets are mostly online (because of the very low transaction cost of information flows online) and run by private companies. Amazon operates a data-rich market, and so do Google, Apple, Facebook, Alibaba, etc., but also current niche players such as Airbnb or Spotify. Consumers prefer such marketplaces because of the superior matching experience compared to most conventional markets, enabling them to share information with their peers, the other market 'customers'. But for this matching to happen, they also have to share their information with the market providers Market providers are the central conduit and know everything about everyone on the market that can be gleaned online. This is a tremendous (and potentially troubling) concentration of power.

A large part of this market consists of (or incorporates elements from) what is known as 'social media' or 'social networks' - platforms for people to exchange information. Where they communicate. The ninth chapter is written by Sandra Petronio, who writes about privacy in communication sciences. She stresses that the nature of privacy has long been a part of the human condition, yet, our attention to this important aspect of life, where individuals need both privacy and the ability to be social with others is in constant need of new discoveries. A mission of communication privacy management theory is to bring new insights into this phenomenon. The mission is to push these ideas further and help others to advance their interests in privacy inquiries. Petronio has developed the Communication Privacy Management Theory, which helps to understand privacy challenges and provides for teaching tools and devising ways to translate research into meaningful practice to help others.

This dual manifestation of privacy in 'freedom from' and 'freedom to' has been extensively analysed by Anita Allen. the author of the tenth and final snippet. The title refers to her ground-breaking book: Uneasy Access: Privacy for Women in a Free Society. This was not only the first book-length treatment of privacy by a philosopher to focus on women, it was the first book-length treatment by an academic philosopher to focus on any aspect of privacy. The work was a response both to the academic debates about the meaning and value of privacy found in analytic-style philosophy journals; and to feminist critiques of privacy emanating from many disciplines. While conceding that women have historically lived their lives as ancillaries and inferiors, Allen argued in Uneasy Access that they have had 'too much of the wrong kind of privacy'. After this, we zoom out for the last time to explore 
other(s) social practices and to what extent these are being studied and analysed as privacy practices - or from a privacy perspective to begin with.

The tenth and final chapter is written by Sjaak van der Geest and engages with an anthropological perspective on privacy. He argues that the old definitions and concepts of privacy still provide fruitful starting points for the exploration of meanings and experiences around privacy, in varying social and cultural settings. The chapter shows privacy as a dynamic process of having control over what one wants to share with selected others, and what not. Importantly, he points out that there is a relative neglect of privacy described as such by anthropologists, although working in other cultures and living closely with their interlocutors confronted them with striking differences in local managements and experiences of privacy. Observations about this however remained largely implicit in their ethnographic work. These indirect allusions to privacy can be found in debates about shame, social manners, witchcraft, family life, stigmatization (HIV/AIDS), gossip, secrets, lying, and disgust.

We hope that this book will help researchers around the globe to understand each other's disciplines and inspire interdisciplinary privacy research. We hope that students will find in the Handbook of Privacy Studies a reliable and intelligible introduction in to the enormous world of privacy research, and that it enables them to use the knowledge it contains in their careers. Finally, we hope that this book will help anyone interested in the subject, to gain a better grasp of privacy, to critically reflect on its role in current society. We hope you enjoy reading The Handbook of Privacy Studies!

Bart van der Sloot \& Aviva de Groot 


\section{About the Authors}

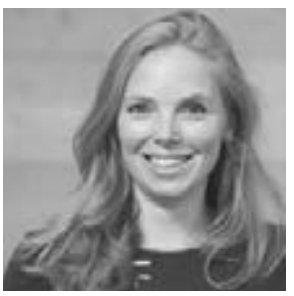

W.J.M. Aerdts LLM MA is a lecturer employed by the department of Intelligence \& Security of the Institute of Security and Global Affairs (Leiden University, the Netherlands). Before, she used to work for the University of Amsterdam where she taught courses for the minor Intelligence Studies. During her time at the Dutch Ministry of Foreign Affairs, Willemijn conducted research on the Western Balkan. Nowadays, her research focusses on intelligence methodology, analysis techniques and oversight. Willemijn is a Worldconnector and a board member of the Netherlands Intelligence Security Association (NISA).

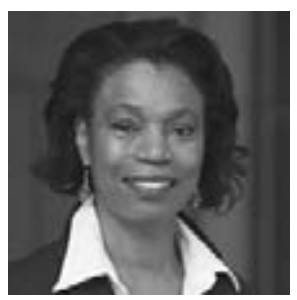

Anita L. Allen is an expert on privacy law, the philosophy of privacy, bioethics, and contemporary values, and is recognized for scholarship about legal philosophy, women's rights, and race relations. She is a graduate of Harvard Law School and received her Ph.D. in Philosophy from the University of Michigan. She was the first African American woman to hold both a PhD in philosophy and a law degree. She was an Associate Attorney with Cravath, Swaine and Moore At Penn she is the Vice Provost for Faculty and the Henry R. Silverman Professor of Law and Professor of Philosophy. She was elected to the National Academy of Medicine in 2016. In 2010 she was appointed by President Obama to the Presidential Commission for the Study of Bioethical Issues.

Her books include Unpopular Privacy: What Must We Hide (Oxford, 2011); The New Ethics: A Guided Tour of the 21st Century Moral Landscape (Miramax/Hyperion, 2004); Why Privacy Isn't Everything: Feminist Reflections on Personal Accountability (Rowman and Littlefield, 2003); and Uneasy Access: Privacy for Women in a Free Society (Rowman and Littlefield, 1988), the first monograph on privacy written by an American philosopher. Her textbooks include: Privacy Law and Society (Thomson/West, 2016), the most comprehensive textbook on the US law of privacy and data protection on the market, with chapters on the common law, constitutional law, federal statutory law, surveillance law and international standards.

Allen, who has published more than a hundred scholarly articles, book chapters and essays, has also contributed to popular magazines, newspapers and blogs, and has frequently appeared on nationally broadcast television 
and radio programs. Allen is active as a member of editorial, advisory, and charity boards, and in professional organizations relating to her expertise in law, philosophy and health care. Elected President of the American Philosophical Association (Eastern) in 2018, she was a member of the NIH Precision Medicine IRB, and has served on the boards of the Hastings Center, the Bazelon Center for Mental Health Law, and the Electronic Privacy Information Center.

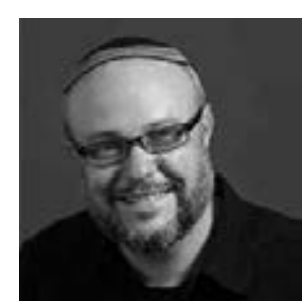

Kenneth A. Bamberger is The Rosalinde and Arthur Gilbert Foundation Professor of Law at the University of California, Berkeley. He is Faculty co-Director of the Berkeley Center for Law and Technology (BCLT) and of the Berkeley Institute for Jewish Law and Israel Studies, and is a core faculty member of the Berkeley Center for Law and Business (BCLB).

Prof. Bamberger is an expert on government regulation, corporate compliance, and technology in both the United States and Europe. At Berkeley, he teaches Administrative Law; the First Amendment (Speech and Religion); Corporate Compliance; the Law and Technology Workshop; and Jewish Law. For his recent book, Privacy on the Ground:Driving Corporate Behavior in the United States and Europe_(MIT Press), Bamberger and his co-author, Berkeley I-School Prof. Deirdre Mulligan, were awarded the 2016 Privacy Leadership Award from the International Association of Privacy Professionals. His articles on "Platform Market Power," and "Saving Governance-by-Design," will be published in 2018.

Bamberger graduated from Harvard Law School, where he was President of the Harvard Law Review. Before coming to Berkeley Law, he clerked for federal appeals court Judge Amalya L. Kearse and U.S. Supreme Court Justice David H. Souter, served as a Bristow Fellow in the Office of the United States Solicitor General, and was an associate, and then counsel, at the Wilmer Hale firm in Washington DC.

Outside the law school, Prof. Bamberger has served on the advisory boards of the Future of Privacy Forum, the Israel Institute, and The Taube Foundation for Jewish Life; on the Program Committee for the European Privacy Law Scholars Conference (PLSC); and on the ADL's Anti-Cyberhate Working Group. In the fall of 2017, he was selected for the U.S. Department of Commerce-European Commission list of arbitrators developed as part of the EU-U.S. Privacy Shield Framework.

From 2013-2015, Bamberger was the first co-chair of UC Berkeley's Center for Jewish Studies. He has been a Visiting Professor at Tel Aviv University 
Law School, a Visiting Fellow at the Shalom Hartman Institute in Jerusalem, and he is a founding board member of the U.S.-Israel Tech Policy Institute.

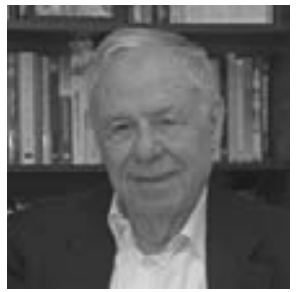

Amitai Etzioni is a University Professor and Professor of International Relations at The George Washington University. He served as a Senior Advisor at the Carter White House, taught at Columbia University, Harvard University, and the University of California at Berkeley, and served as president of the American Sociological Association (ASA). A study by Richard Posner ranked him among the top 100 American intellectuals. He is the author of numerous op-eds and his voice is frequently heard in the media. He is the author of many books, including The Active Society, The Moral Dimension, The New Golden Rule, My Brother's Keeper - and most recently Happiness is the Wrong Metric. And two books on privacy, The Limits of Privacy (1999) and Privacy in a Cyber Age: Policy and Practice (2015).

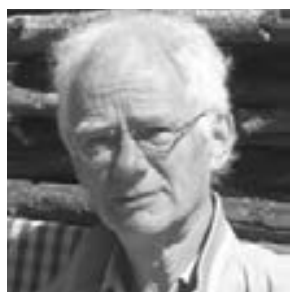

Sjaak van der Geest is emeritus professor of Medical Anthropology at the University of Amsterdam. He has done fieldwork in Ghana and Cameroon on a variety of subjects including sexual relationships and birth control, the use and distribution of medicines, popular song texts, meanings of growing old, and concepts of dirt and hygiene. His interest in privacy is of a more recent date and enables him to reflect on fieldwork experiences throughout his anthropological career. He was the founder and editor-in-chief of the journal Medische Antropologie (now: Medicine Anthropology Theory - MAT) and assistant editor of several other journals in the field of medical anthropology. Website: www.sjaakvandergeest.nl

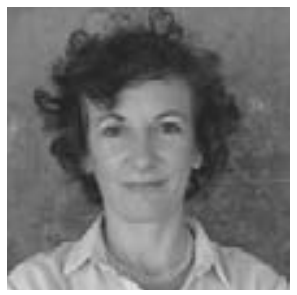

Aviva de Groot is a $\mathrm{PhD}$ researcher at the Tilburg Institute for Law, Technology, and Society. With her research, she aims to identify explanatory benchmarks and modalities for providing rights relevant understanding of data driven technologies and their applications to laymen users. In particular, she focusses on automated decision making processes. With privacy at the core, her interests more broadly concern humans and technology, their mutual shaping and how this effects our understanding of human rights protections. She has professional and research experience in fields 
where technology supports human interaction and where humans interact with machines. As concerns the former, in dumber times, the transformation of citizens' reality to their administrative truth already proved to be a tricky process. Years of professional legal experience in a specialized field of administration law, dealing with phantom vehicle registrations, taught her how the complex interplay of law, policy and technology should discourage a narrow a focus on either element. Her Information Law master's thesis research project dealt with privacy concerns arising from the use of social robots in health care settings. She focused in particular on levels of transparency and understanding of human-robot interaction.

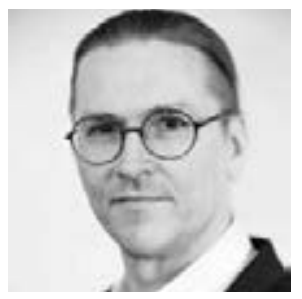

Mikko Hypponen is a worldwide authority on computer security and the Chief Research Officer of F-Secure. He has written on his research for the New York Times, Wired and Scientific American and lectured at the universities of Oxford, Stanford and Cambridge. He sits in the advisory boards of EUROPOL and the Monetary Authority of Singapore.

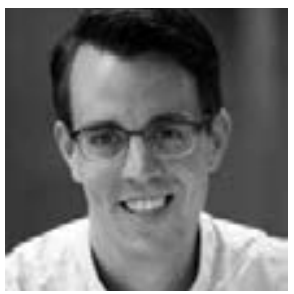

Sjoerd Keulen is an assistant professor of public administration at the Erasmus University, Rotterdam. Sjoerd read both History and International Relations at the University of Groningen. Sjoerd wrote his PhDthesis at the University of Amsterdam on the post-war history of changing ideal types of policy making in the Netherlands. Thereafter he was a researcher for the parliamentary enquiry on housing associations of the Netherlands House of Representatives and a senior advisor at the Inspectorate of the Budget of the Netherlands Ministry of Finance. Sjoerd's research focuses on qualitative analyses of accountability, policy evaluation and on connecting history to financial management and budgetary policy. Together with Ronald Kroeze Sjoerd published on management history and leadership in management journals and history journals. 


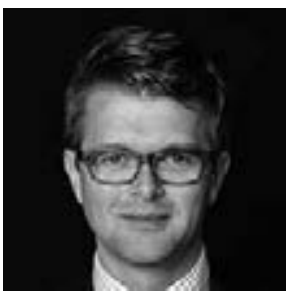

Dr. Wouter Koelewijn wrote his dissertation at the eLaw, Center for and Digital Technologies of the University of Leiden, on electronical exchanges of sensitive personal data in the policing domain. He worked as a lawyer specialized in health care governance \& finance, and as advisor and senior manager for PWC in the health care domain. He currently works as health care lawyer and partner of Van Benthem \& Keulen and also as associate professor Health Law at Amsterdam University. Wouter also teaches postacademic courses on Privacy \& Data Protection.

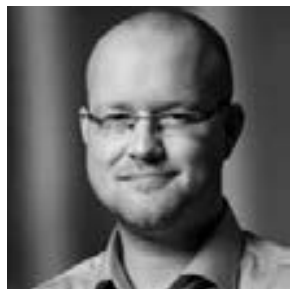

Matthijs Koot is employed as IT security specialist at Secura BV, and is guest researcher at the System and Network Engineering laboratory of the University of Amsterdam. Matthijs holds a MSc in System \& Network Engineering (2005-2006) and a PhD in data anonymity (2007-2011) from the University of Amsterdam. In his work for Secura (previously known as Madison Gurkha) he has over six years of experience in, among others, testing security of computer systems and networks, social engineering, red teaming, code reviews, design reviews, and supporting privacy-by-design and security-by-design practices. In 2018 he joined as board member of the Netherlands Intelligence Studies Association (NISA).

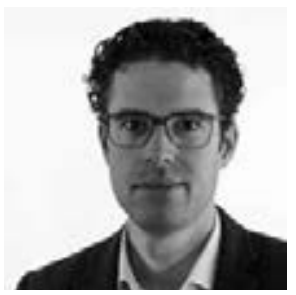

Ronald Kroeze is an Assistant Professor of History at the Vrije Universiteit Amsterdam. He teaches courses on European history, democracy, corruption and global justice. In his research and publications, he focuses on the history of governance, transparency, privacy, democracy and (anti)corruption as well as the history of management and leadership. A recent publication is Ronald Kroeze, Guy Geltner and André Vitoria (eds.), A History of Anticorruption. From Antiquity until the Modern Era. Oxford: Oxford University Press, 2018. On his research he has also published in Journal for Modern European History, BMGN-Low Countries Historical Review, Management \& Organizational History and Business History. Kroeze was a postdoctoral researcher at the University of Amsterdam and a research fellow at Humboldt University, Warwick University and University of Avignon. He is a member of the Amsterdam Centre for Political Thought and the European Research Network 'Politics and corruption: history and sociology', funded by the CNRS. 


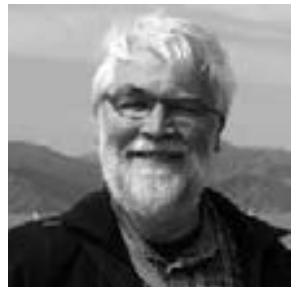

Prof.dr.ir. Cees de Laat chairs the System and Network Engineering (SNE) laboratory at the Faculty of Science at University of Amsterdam. The SNE lab conducts research on leading-edge computer systems of all scales, ranging from global-scale systems and networks to embedded devices. Across these multiple scales our particular interest is on extra-functional properties of systems, such as performance, programmability, productivity, security, trust, sustainability and, last but not least, the societal impact of emerging systems-related technologies. Cyber Infrastructure is rapidly evolving from relatively simple fixed components to programmable and virtualized objects with many degrees of freedom, owned and operated by different entities in multiple administrative connected domains on the Internet. Harnessing this complexity in a transparent trust-able way for safe and secure data processing is a major research topic that nowadays defines the focus of his research. For current activities and projects see: http://delaat.net/.

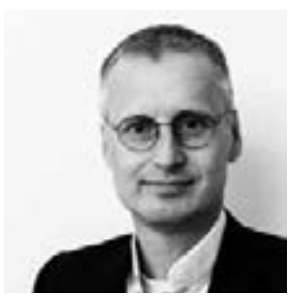

Viktor Mayer-Schönberger is Professor of Internet Governance and Regulation at the University of Oxford. In addition to his recent book "Reinventing Capitalism in the Age of Big Data" with Thomas Ramge) and the best-selling "Big Data" (with Kenneth Cukier), Mayer-Schönberger has published ten books, including the awards-winning "Delete: The Virtue of Forgetting in the Digital Age" and is the author of over a hundred articles and book chapters on the information economy. After successes in the International Physics Olympics and the Austrian Young Programmers Contest, Mayer-Schönberger studied in Salzburg, Harvard and at the London School of Economics. In 1986 he founded Ikarus Software, a company focusing on data security and developed the Virus Utilities, which became a best-selling Austrian software product. He advises governments, businesses and NGOs on new economy and information society issues.

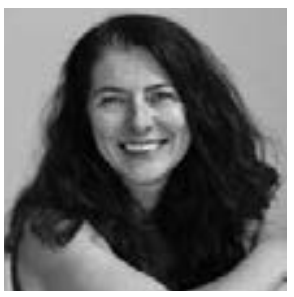

Deirdre K. Mulligan is an Associate Professor in the School of Information at UC Berkeley, and a faculty Director of the Berkeley Center for Law \& Technology. Mulligan's research explores legal and technical means of protecting values such as privacy, freedom of expression, and fairness in emerging technical 
systems. Her book, Privacy on the Ground: Driving Corporate Behavior in the United States and Europe, a study of privacy practices in large corporations in five countries, conducted with UC Berkeley Law Prof. Kenneth Bamberger was recently published by MIT Press. Mulligan and Bamberger received the 2016 International Association of Privacy Professionals Leadership Award for their research contributions to the field of privacy protection. Mulligan is currently serving on the Defense Advanced Research Projects Agency's Information Science and Technology Advisory Board, the Board of Directors of the Center for Democracy and Technology, a leading advocacy organization protecting global online civil liberties and human rights, and the Board of the Partnership for AI. Prior to joining the School of Information. Mulligan began her academic career as a Clinical Professor of Law, the founding Director of the Samuelson Law, Technology \& Public Policy Clinic, and Director of Clinical Programs at the UC Berkeley School of Law. Prior to Berkeley, she served as staff counsel at the Center for Democracy \& Technology in Washington, D.C. Mulligan holds a JD from Georgetown University Law Center and a BA from Smith College.

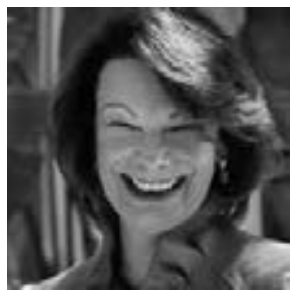

Sandra Petronio is Founding Director of Communication Privacy Management Center at IUPUI, Professor, Department of Communication Studies in the Indiana University and IU School of Medicine, Senior Affiliate Faculty in Fairbanks Center for Medical Ethics. Served as Founding Director Translating Research into Practice Center. Received B.A State University of New York at Stony Brook, received M.A. and Ph.D. University of Michigan. Studies privacy, disclosure, and confidentiality and developed the evidenced-based "Communication Privacy Management" (CPM) theory examining how people manage their private information. Her 2002 book on CPM theory, "Boundaries of Privacy: Dialectics of Disclosure" won National Communication Association Gerald R. Miller Award and from the International Association of Relationship Research. Petronio published five books, numerous scholarly articles. Received National Communication Association's Bernard J. Brommel Lifetime Award for Excellence in scholarship, received National Communication Association Mark Knapp Scholar's Award for research in Interpersonal, Western States Communication Association Distinguished Scholar Award, and Founding Fellow International Association of Relationship Research. In 2018, received National Communication Association Distinguished Scholar. Email address is: petronio@iupui.edu and www.cpmcenter.iupui. edu 


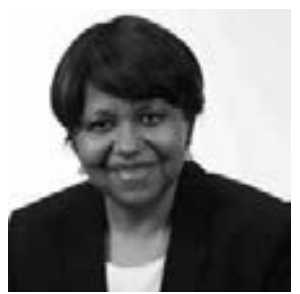

Robin Pierce, JD, $\mathrm{PhD}$, is associate professor at the Tilburg Institute for Law, Technology, and Society (TILT, Tilburg University, The Netherlands). She obtained her law degree (Juris Doctor) from University of California, Berkeley and a PhD from Harvard University where her work focused on genetic privacy. She has taught courses in Data Protection and Privacy, Ethical and Legal Issues in Biotechnology, and Social Issues in Biology. She currently teaches a course on Regulation for the LLM Law \& Technology at Tilburg Law School. Her current research addresses the themes of data protection law and health data, as well as legal, policy and ethical issues regarding $\mathrm{AI}$ in healthcare, and regulation of novel biomedical technologies.

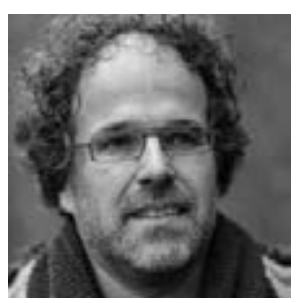

Jo Pierson, Ph.D., is Associate Professor in the Department of Media and Communication Studies at the Vrije Universiteit Brussel (VUB) in Belgium (Faculty of Social Sciences \& Solvay Business School). He is also Senior Researcher and Unit Leader at the research centre SMIT (Studies on Media, Innovation and Technology) since 1996. In this position he is in charge of the research unit 'Privacy, Ethics \& Literacy', in cooperation with imec ( $R \& D$ and innovation hub in nanoelectronics and digital technology). He lectures undergraduate and postgraduate courses at Vrije Universiteit Brussel, Hasselt University and University of Amsterdam, covering socio-technical issues of digital media design and use. Drawing upon media and communication studies, in combination with science and technology studies, his interdisciplinary research focus is on data, privacy, public values and user empowerment in online platforms. He is also elected member of the International Council of the International Association for Media and Communication Research (IAMCR).

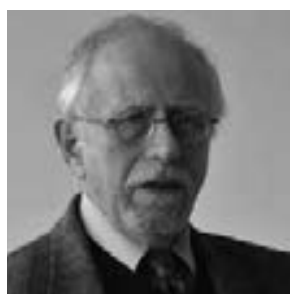

Charles Raab is Professorial Fellow in Politics and International Relations, School of Social and Political Science, University of Edinburgh; Director, Centre for Research into Information, Surveillance and Privacy (CRISP); co-Chair, Independent Digital Ethics Panel for Policing (IDEPP); Fellow, Alan Turing Institute (ATI) and member, ATI Data Ethics Group. Research on privacy, data protection, surveillance, 'smart' environments, security, democracy, identity. Publications include (with C. Bennett), The Governance 
of Privacy: Policy Instruments in Global Perspective (2003; 2006); (with B. Goold), Protecting Information Privacy (2011); (with Surveillance Studies Network), A Report on the Surveillance Society (2006); (with W. Webster et al, eds.), Video Surveillance: Practices and Policies in Europe (2012). Evidence to UK parliamentary committees (e.g., Intelligence and Security Committee, 2014); Specialist Adviser, House of Lords Constitution Committee for inquiry, Surveillance: Citizens and the State, HL Paper 18, Session 2008-09. Fellow, Academy of Social Sciences; Fellow, Royal Society of Arts.

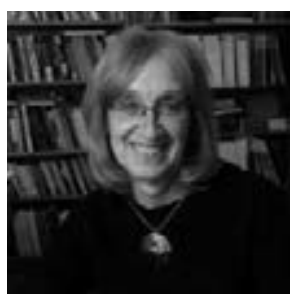

Dr. Priscilla Regan is a Professor in the Schar School of Policy and Government at George Mason University. Prior to joining that faculty in 1989 , she was a Senior Analyst in the Congressional Office of Technology Assessment (1984-1989) and an Assistant Professor of Politics and Government at the University of Puget Sound (1979-1984). From 2005 to 2007, she served as a Program Officer for the Science, Technology and Society Program at the National Science Foundation. Since the mid-1970s, Dr. Regan's primary research interests have focused on both the analysis of the social, policy, and legal implications of organizational use of new information and communications technologies, and also on the emergence and implementation of electronic government initiatives by federal agencies.

Dr. Regan has published over forty articles or book chapters, as well as Legislating Privacy: Technology, Social Values, and Public Policy (University of North Carolina Press, 1995). As a recognized researcher in this area, Dr. Regan has testified before Congress and participated in meetings held by the Department of Commerce, Federal Trade Commission, Social Security Administration, and Census Bureau. She has received grants from the National Science Foundation. She was a member of the National Academy of Sciences, Computer Science and Telecommunications Board, Committee on Authentication Technologies and their Privacy Implications. Dr. Regan received her $\mathrm{PhD}$ in Government from Cornell University and her BA from Mount Holyoke College.

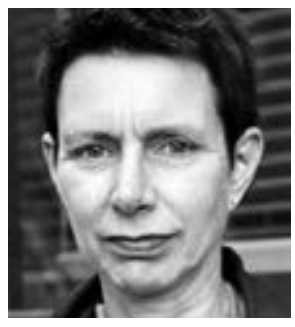

Beate Roessler is Professor of Philosophy at the University of Amsterdam. She formerly taught philosophy at the Free University, Berlin, Germany, and at the University of Bremen, Germany. She was a fellow at the Institute for Advanced Study (Wissenschaftskolleg) in Berlin, at the Center for Agency, Value, and Ethics at Macquarie University, Sydney, a 
two-month fellow at the University of Melbourne, Law School and a visiting professor at the New York University. She is a co-editor of the European Journal of Philosophy and a member of various advisory boards.

Her publications include Social Dimensions of Privacy. Interdisciplinary Perspectives (ed. with D. Mokrosinska), Cambridge UP 2015; "Meaningful Work: Arguments from Autonomy", in:Journal of Political Philosophy 2012; The Value of Privacy, Polity Press 2005; Privacies. Philosophical Evaluations, (ed.), Stanford University Press, 2004. Her book Autonomie: ein Versuch über das gelungene Leben, was published in 2017 and will be published in English in 2019.

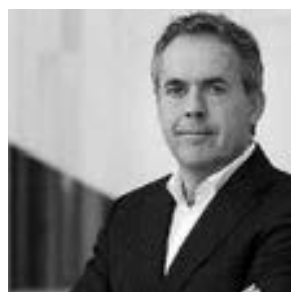

Edo Roos Lindgreen is professor of Data Science in Auditing at the University of Amsterdam. He is one of the co-founders of the Amsterdam Platform for Privacy Research and member of the organizing committee of the Amsterdam Privacy Conference. He serves as the program director for the Executive Programme of Digital Auditing and the Executive MSc of Internal Auditing at the Amsterdam Business School. Until 2018, he was a partner at KPMG Advisory N.V.

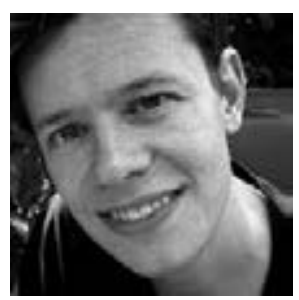

Marijn Sax is a $\mathrm{PhD}$ candidate at the Institute for Information Law and Department of Philosophy of the University of Amsterdam. He has a background in Political Science (BSc.) and Philosophy (BA., MA., both cum laude) and is mainly interested in questions concerning ethics, privacy and technology. Marijn's research focuses on health apps, and more specifically on the ethical dimensions of this new phenomenon and how ethical considerations can inform legal regulation. Marijn's research is part of the Personalised Communication project.

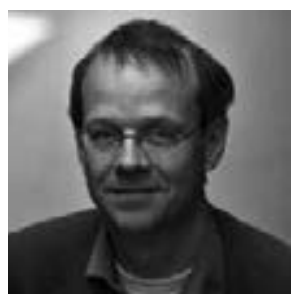

Dr. Tjeerd Schiphof is assistant professor at the University of Amsterdam. Since long he has specialized in Information Law, more in particular with regard to art, media and cultural heritage. The study of privacy concerns in the archival sector is one of his research objects. He is affiliated to the Bachelor programme Media and Information, and the Master programme Archival Studies, both being offered by the UvA department of Media Studies. 


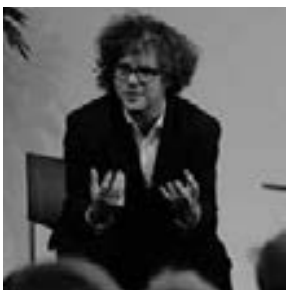

Bart van der Sloot specializes in Privacy and Big Data. He also publishes regularly on the liability of Internet Intermediaries, data protection and internet regulation. Bart has studied philosophy and law in the Netherlands and Italy and has also successfully completed the Honours Programme of the Radboud University.

He currently works at the Tilburg Institute for Law, Technology, and Society of the University of Tilburg, Netherlands. Bart formerly worked for the Institute for Information Law, University of Amsterdam, and for the Scientific Council for Government Policy (WRR) (part of the Prime Minister's Office of the Netherlands) to co-author a report on the regulation of Big Data in relation to security and privacy.

Bart van der Sloot is the general editor of the international journal European Data Protection Law Review and board member of the European Human Rights Cases. Bart also is the scientific director of the Privacy \& Identity Lab.

Finally, Bart van der Sloot is the coordinator of the Amsterdam Platform for Privacy Research (APPR), which consists of about 70 employees at the University of Amsterdam who in their daily teaching and research activities focus on privacy-related issues. In that position, he also founded the minor Privacy Studies, an interdisciplinary minor at bachelor level about privacy and new technological developments. Previously, he was the conference coordinator of the Amsterdam Privacy Conference 2012, 2015 and 2018.

Personal website: www.bartvandersloot.com

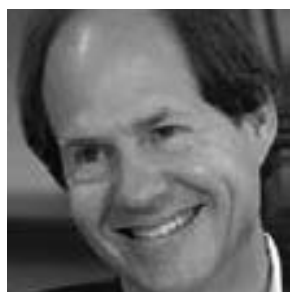

Cass R. Sunstein is currently the Robert Walmsley University Professor at Harvard. From 2009 to 2012, he was Administrator of the White House Office of Information and Regulatory Affairs. He is the founder and director of the Program on Behavioral Economics and Public Policy at Harvard Law School. Mr. Sunstein has testified before congressional committees on many subjects, and he has been involved in constitution-making and law reform activities in a number of nations.

Mr. Sunstein is author of many articles and books, including Republic. com (2001), Risk and Reason (2002), Why Societies Need Dissent (2003), The Second Bill of Rights (2004), Laws of Fear: Beyond the Precautionary Principle (2005), Worst-Case Scenarios (2001), Nudge: Improving Decisions about Health, Wealth, and Happiness (with Richard H. Thaler, 2008), Simpler: 
The Future of Government (2013) and most recently Why Nudge? (2014) and Conspiracy Theories and Other Dangerous Ideas (2014). He is now working on group decisionmaking and various projects on the idea of liberty.

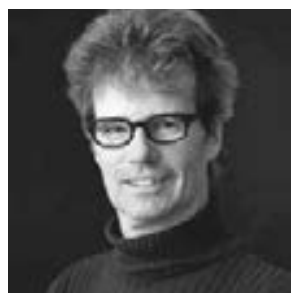

Giliam de Valk is, since 2016, an assistant professor at the Institute of Security and Global Affairs (ISGA) of Leiden University. He lectures and researches on intelligence, analysis and methodology. He wrote his dissertation (2005) at the Law Faculty of University of Groningen on the quality of intelligence analyses. Before, he has worked at the University of Amsterdam and the Netherlands Defense Academy in Breda, and at both institutes he initiated and coordinated a minor on intelligence studies. Besides on intelligence, he has lectured on issues as strategy, humanitarian intervention, counterinsurgency, terrorism and counter-terrorism. From 2004-2012, he had been the secretary of the Netherlands Intelligence Security Association (NISA), of which he is still a board member.

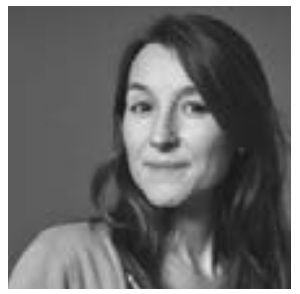

Ine van Zeeland MA is a $\mathrm{PhD}$ researcher at the Studies in Media, Innovation and Technology (SMIT) research centre at the Vrije Universiteit Brussel, which is afflliated with R\&D hub imec. She mostly works on research projects around privacy and data protection, with occasional excursions into algorithmic accountability and digital literacy. Her main focus is on the day-to-day tactics of data protection professionals, as well as organisational efforts to comply with the European Union's General Data Protection Regulation (GDPR). 